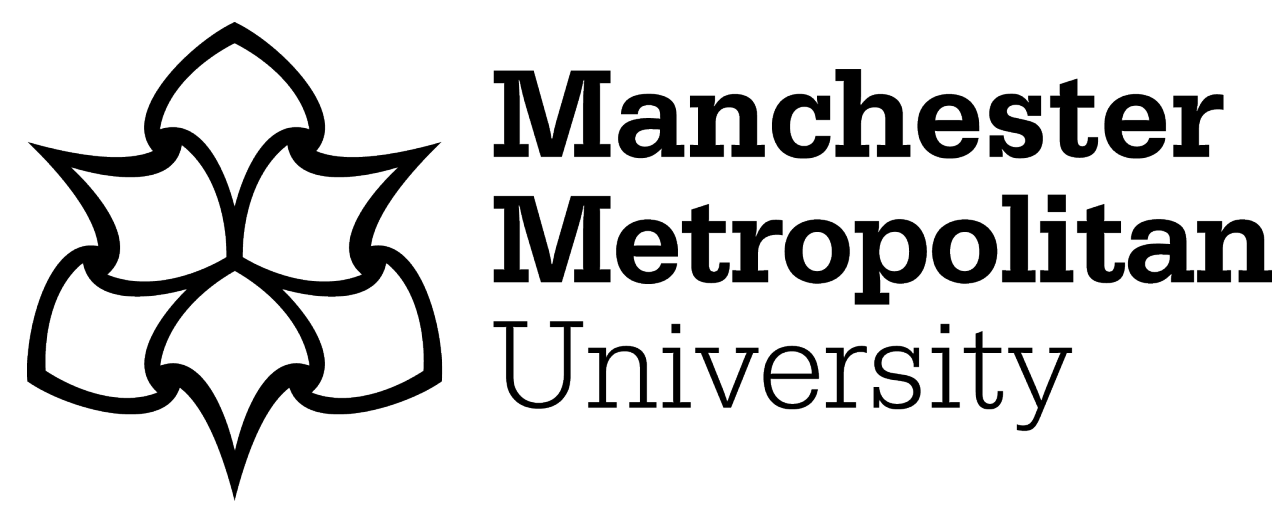

Kolić, PV, Groom, R, Nelson, L and Taylor, WG (2020) (Dis)joint(ed) action, reciprocity, and professional status: an ethnographic investigation of two UKCC CL4 awards. Sport, Education and Society, 25 (9). pp. 1043-1057. ISSN 1357-3322

Downloaded from: https://e-space.mmu.ac.uk/624477/

Version: Accepted Version

Publisher: Taylor \& Francis

DOI: https://doi.org/10.1080/13573322.2019.1687443

Please cite the published version 
(Dis)joint(ed) action, reciprocity, and professional status: An ethnographic investigation of two UKCC CL4 awards

Accepted for publication 29/10/19

Petra Kolic a $^{*}$, Ryan Groom ${ }^{\mathrm{a}}$, Lee Nelson ${ }^{\mathrm{b}}$ and William G. Taylor ${ }^{\mathrm{a}}$

${ }^{a}$ Department of Sport and Exercise Sciences, Manchester Metropolitan University,

Manchester, United Kingdom; ${ }^{b}$ Department of Sport and Physical Activity, Edge Hill

University, Ormskirk, United Kingdom

*Corresponding author. Department of Sport and Exercise Sciences, Manchester Metropolitan University, Oxford Road, Manchester M15 6BH, UK. Email:

P.Kolic@mmu.ac.uk. ORCiD ID: https://orcid.org/0000-0003-3402-1857

To cite:

Kolić, Groom, R., Nelson, L., and Taylor, W. G. (2019). (Dis)joint(ed) action, reciprocity, and professional status: An ethnographic investigation of two UKCC CL4 awards. Sport, Education and Society. DOI: 10.1080/13573322.2019.1687443 


\title{
(Dis)joint(ed) action, reciprocity, and professional status: An ethnographic investigation of two UKCC CL4 awards
}

\author{
Coach education research has focused on studying coaches' perspectives about \\ coach education programmes with limited studies investigating the practices of \\ other key stakeholders involved in programme design and delivery (e.g. \\ managers, educators). The purpose of this study was to investigate the \\ interactions and practices of coaches, coach educators, and coach education \\ managers in two contexts of the United Kingdom Coaching Certificate Coach \\ Level 4 (UKCC CL4) award. Over a period of 18 months, ethnographic \\ fieldwork was conducted with 53 participants, comprising of 250 hours of \\ participant observations and informal conversations, as well as 51 semi- \\ structured interviews. Symbolic interactionist writing by Blumer (1946; 1969), \\ Mead (2015), and Strauss (1997) was utilised to make sense of the processes, \\ relations, and tensions created by the UKCC CL4 award. The themes explore \\ consequences and challenges of novel collaborations between course organisers \\ from Governing Bodies (GB) and Higher Education institutions (HEi), \\ opportunities and issues arising when university lecturers mediate theoretical \\ course content for practitioner cohorts, and the value of postgraduate study to \\ coaches' professional lives.
}

Keywords: Coach education; Learning; Postgraduate study; Elite coaches; Coach educators; Ethnography; Fieldwork; Symbolic interactionism 


\section{Introduction}

Higher education programmes that are designed and delivered to support professionals in the field, should develop learners' subject-specific knowledge, enhance their ability to apply theory in the workplace, and encourage critical and reflective conduct (Trede, Macklin, \& Bridges, 2012). The mediation of programme design and delivery is particularly important for adult learners, as the move from familiar professional milieus to possibly unknown territories of higher education can challenge longstanding vocational understandings and professional identities (Bandias, Fuller, \& Pfitzner, 2011). The conduct of educational providers therefore is significant to support and negotiate with learners the transition into education (Willans \& Seary, 2011). Devlin and Samarawickrema (2010) explain that educators play an important role in this process, and that the effective delivery of higher education must extend beyond robust subject knowledge. Moreover, in this context it is also important to recognise that mature learners are heterogeneous groups, and often draw on established practices and roles (Devlin \& Samarawickrema, 2010). For example, using learners' established ways of thinking as stepping stones to new understandings (Spies \& Botma, 2015), providing opportunities for learners to share existing knowledge (Willans \& Seary, 2011), and creating environments that facilitate exchange (Chugai, Terenko, \& Ogienko, 2017) contribute to the development of delivery approaches that align course contents with the bespoke needs of adult learners. In turn, this can shape feelings of success and confidence in academic situations and aid the development of positional identities in higher education environments (Kasworm, 2010).

Sports coaches represent one group of professionals, who return to education throughout their careers to inform continuous development (Werthner \& Trudel, 2009) and develop athlete-appropriate, quality practice (Townsend \& Cushion, 2017). 
Research into coach education has sought to explore actual and preferred sources of knowledge and demonstrated that coach education programmes are not necessarily useful to practice, particularly when compared to less structured learning opportunities, such as specialist workshops, peer interactions, and day-to-day coaching (e.g., He, Trudel, \& Culver, 2018). Although coaches recognise coach education programmes as integral components to lifelong learning (Werthner \& Trudel, 2009), largely, they seem to associate the content taught in these formal settings with limited transferability and relevance to practice. For instance, a longitudinal study by Jones and Allison (2014) of an advanced coach education programme revealed that coach learners perceived a competency-based nature of delivery and assessments difficult to implement in practice and led coaches to focus on course content that fitted with existing practice and interactions with those, who endorsed longstanding beliefs. Comparable suggestions followed a study by Townsend and Cushion (2017) of a postgraduate coach education programme, namely the cricket United Kingdom Coaching Certificate Coach Level 4 (UKCC CL4) award. The study revealed coaches' frustrations when engaging with scientific course content that was deemed contradictory to legitimate knowledge concerning their sport (Townsend \& Cushion, 2017). Coaches' perceived discrepancies between course content and delivery approaches encountered in educational environments and their established expertise challenged professional identities and led coaches to act protectively of deep-rooted knowledge leaving little openness to novel, theoretical, or scientific understandings (Townsend \& Cushion, 2017). In such instances, coaches' perceived impact of coach education programmes remained superficial at best (Jones \& Allison, 2014) and led coaches to resort to familiar, trusted strategies in day-to-day coaching practice (Chesterfield, Potrac, \& Jones, 2010). 
Mainstream research has given consideration toward how higher education delivery is far from apolitical but instead negotiated between key stakeholders (Bandias et al., 2011; Spies \& Botma, 2015). It has further investigated how mature learners received delivery methods (Chugai et al., 2017; Damşa \& Ludvigsen, 2016) and what impact this may have on their professional identities (Kasworm, 2010; Willans \& Seary, 2011). Such avenues of inquiry have not yet been explored in the area of sports coaching. Rather, previous research has revealed coaches' preferences regarding delivery approaches and types of learning with inquiries rarely extending beyond retrospective accounts of coaches' experiences with coach education (e.g., Chesterfield et al., 2010; He et al., 2018; Townsend \& Cushion, 2017). Little is known about what happens in coach education environments, about how key stakeholders interact with one another (e.g. learners and educators, educators and managers), and about the meanings of these interactions to the stakeholders. One approach that has been useful to studying processes occurring in educational environments in situ is ethnographic fieldwork (Lucas, 2012). Studies into higher education suggested that ethnographic fieldwork allows the researcher to extend their inquiry beyond learner experiences by observing education spaces over prolonged periods from viewpoints of different individuals involved in everyday situations of education (Iloh \& Tierney, 2014). It facilitates in-depth understanding of how key stakeholders see and interpret educational situations and aids exploration of the meanings that different encounters of learners might have to them as individuals (Cousin, 2009).

Therefore, the aim of the present study was to investigate the interactions and their subsequent meaning in postgraduate coach education across a range of stakeholders. To achieve this, two case study Governing Bodies (GBs) working in conjunction with different Higher Education institutions (HEi) represented the research 
sites for the present study. Ethnographic fieldwork was adopted to respond to the following research questions:

- How and why did the social relations between key stakeholders impact on the design, management, and delivery of the studied coach education programmes?

- How did the expectations of coach educators and learners affect how learners experienced, perceived, and responded to the programme of study?

- What value did the coach learners attach to the qualification and how were their opinions shaped by their social interactions with others?

At the heart of this investigation is the desire to contribute toward new knowledge in the field of coach education and coach learning through developing an in-depth appreciation of the interactions between key stakeholders and the meanings these stakeholders attach to such educational relations. Grounded on a robust and extended period of ethnographic fieldwork, this study goes someway to answer the call for fieldbased research to capture the dynamic subtleties underpinning interactions between key stakeholders within education spaces. The insights gained from the present study serve not only to advance empirical understandings of educational interactions in practice, but may also practically inform the policy decisions, design, and delivery of high-level coach education provision. This is important because it may help key stakeholders give consideration towards responsibilities and relationships of those involved in the design of coach education and may usefully inform decisions with regarding those who deliver coach education and how they can be supported in the development of researchinformed and coaching-relevant coach education. 


\section{Methodology}

\section{Research context: The UKCC CL4 award}

The UKCC CL4 award represents the highest qualification that coaches can obtain in the UKCC scheme (a standardised coach education framework established by UK Coaching), for which purpose, GBs and HEis develop courses that adhere to Level 4 criteria and academic standards at UK postgraduate level 7 (Sports Coach UK, 2015). Largely distance learning in nature, coaches also attend 10-12 days of face-to-face delivery over a period of 24 months. During this time, coaches complete modules relating to sport sciences, social sciences, and professional skills. Coaches must attend the residential days, pass module assessments, and deliver a viva of their independent study to qualify as UKCC CL4 Performance Coaches and to obtain a Postgraduate Diploma (PG Dip). The latter enables continuation of HEi studies at UK Masters Degree level.

For the purpose of this study, the final author held initial conversations with a contact at UK Coaching, who was supportive of a qualitative inquiry into the UKCC CL4 award. It was decided that the research team would agree on the approach most suitable to their expertise to investigate the everyday realities of the award. Following these initial conversations, the UK Coaching contact aided the principal author to communicate with coaches, coach educators, and coach education managers in interested GBs and HEis the scope of the research. This led to field-based research with two case study GBs. Of 53 participants, 33 stakeholders were involved in a combat sport course offered in collaboration with one HEi and 20 stakeholders engaged with a water sport programme offered in collaboration with another university (Appendix 1). 


\section{Ethnographic fieldwork}

This study was informed by ethnographic fieldwork to gain insight into the interactions and practices of coaches, coach educators, and coach education managers "from within the everyday contexts" of the UKCC CL4 award (McCall, 2006). Characterised by prolonged engagement with the research field, ethnographic fieldwork allows the researcher to observe, listen, and ask questions that aid interpretations in the imminent contexts of inquiry (Hammersley \& Atkinson, 2007). In this study, the principal author immersed herself in the CL4 delivery days over a period of 18 months to make sense of participant perspectives in unrehearsed, "natural" situations. The flexible nature of this approach rendered opportunity to refine and evolve questions over the course of the fieldwork (Wolcott, 2008), which was considered valuable to develop in-depth understandings of stakeholder interactions and their meanings.

\section{Data collection}

\section{Participant observations and field notes}

Participant observations are a common ethnographic research method and facilitate the development of intimate knowledge of areas under study (e.g., Atkinson, 2017; Wolcott, 2008). In this study, the principal author experienced first-hand the everyday running of UKCC CL4 delivery days through 250 hours of participant observations and everyday conversations (Hammersley \& Atkinson, 2007). Her role shifted between a peripheral member, who quietly observed sessions, and that of an active-member researcher, who interacted freely with participants over coffee and meals (Adler \& Adler, 1987). As writing is part of ethnographic inquiry (Atkinson, 2017), data were 
recorded in 200 hand-written pages of field notes. Writing encompassed an "active process of sense-making" that allowed the interweaving of observed events with impromptu thoughts and interpretations (Emerson, Fretz, \& Shaw, 2001, p. 353). Focus was on processes relevant to the research objectives. In particular, on the environments created during programme delivery days, on how coach education managers interacted in these environments, on how educators (i.e. university lecturers) approached postgraduate delivery and coaches subsequently perceived this delivery, and on how and why coaches valued postgraduate study.

\section{Semi-structured interviews}

Interviews were conducted to complement and expand on the data gleaned from observations and impromptu conversations with participants. Semi-structured interviews represent opportunities to cover aspects that are close to researcher interests, while rendering the flexibility to discuss participant perspectives (Brinkmann \& Kvale, 2018). In ethnographic work, this aids clarification of insights gained from observational data and promotes an in-depth understanding of participant thoughts (Gubrium \& Holstein, 2003). In this study, 38 of the 53 stakeholders (Appendix 2), recruited during residential events, agreed to interview participation. Some were interviewed twice, to expand on initial dialogues, which led the principal author to conduct 51 interviews lasting an average of 38 minutes and ranging from 24 to 63 minutes (Appendix 2). A mixture of face-to-face conversations and Skype video calls, interviews were organised outside the tightly scheduled delivery days at times and locations convenient to participants (Stephens, 2010). 
All interviews occurred from around the time half of the delivery days had taken place or after this point in order to give participants time to form opinions about the UKCC CL4 award. The flow of conversations was relaxed, as the participants knew the researcher from her fieldwork. Beginning with demographic questions, interviews shifted to education, learning, and the UKCC CL4 award more explicitly. Key issues explored included participant experiences and perspectives regarding how the programmes were organised and delivered, how managers, educators, and learners interacted, who delivered the programmes, how coaches responded to this programme delivery, and what the award meant to coaches. Interviews were audio-recorded with participant consent and transcribed (488 pages of transcripts) by the principal author for further interpretation (Bucholtz, 2000).

\section{Ethical considerations}

In line with the principal author's university ethics policy, participants gave written consent before taking part in observations, informal conversations, and semi-structured interviews. Some participants stated a desire for their real names to be used in published material; therefore, not all names are pseudonyms in the results and discussions of this paper. Beyond these procedural steps, ethical conduct represented an ongoing consideration, as the principal author developed relationships with the participants over the course of the fieldwork (Guillemin \& Gillam, 2004). The principal author was transparent about the purpose of her research, openly responded to questions, and gave participants opportunities to revisit and revise the information they had shared during observations, informal conversations, and interviews (Ellis, 2004). 


\section{Data analysis}

The analysis followed an inductive process that was informed by the research questions and aided the thematic organisation of interview data and field notes (Hammersley \& Atkinson, 2007). The principal author read interview transcripts recurrently, defining codes, which constituted of links between data and ideas, and themes that helped identify commonalities and distinctions (Braun, Clarke, \& Weate, 2016). Following suggestions by Atkinson (2017) and Wolcott (2008), field notes were read thoroughly and used thoughtfully to contextualise mundane observations, participant views, and researcher interpretations in a thematic order. Throughout this process, the principal author organised the data around the interactions of stakeholders and the impact these may have on the perspectives of coaches, coach educators, and coach education managers. Analytical questions included "What are the interactions between stakeholders?", "Who is involved in different interactions?", "When and how do interactions occur?", and "What is the impact of these interactions?" To strengthen the credibility of interpretations, the research team acted as critical friends, who challenged the principal author's thoughts and explored with her interpretive avenues (Smith \& McGannon, 2018). In the latter stages, the analysis moved from emic readings of the data in close relation to the research questions toward etic readings with regard to how theory that advances the understandings of coach education in relation to social processes could inform the fieldwork data (Wolcott, 2008).

\section{Theoretical framework}

Symbolic interactionist theorisation was considered particularly fruitful for interpretive purposes. As a "theory of experience and a theory of social structure" (Denzin, 1992, p. 
3), it offered theoretical understandings, which aligned with the research questions and the fieldwork nature of the inquiry. Concerned with how people interpret interpersonal situations, define meaning in those instances, and subsequently act, symbolic interactionism facilitated a view of the UKCC CL4 award as evolving through the interpretive efforts of individual stakeholders and groups (Nelson, Groom, Potrac, \& Marshall, 2016). This was perceived significant to advance the understandings of coach education as an inherently social process by making sense of the meanings that stakeholders defined from interactions with each other, personal experiences, and individual beliefs. In particular, writings by Blumer (1946; 1969), Mead (2015), and Strauss (1997) were used to interpret "emerging, situated acts on the social scene" of UKCC CL4 delivery days (Rock, 2001, p. 29). The work by each theorist was able to provide a reading of different parts of the fieldwork data and, collectively, the theoretical suggestions about the symbolic meanings of interpersonal encounters and their significance to how people act, supported interpretations of educational environments "through observing them, talking and acting in their everyday" settings (Charon, 2010, p. 86).

To understand in greater depth how the conduct and relationships of those, who managed the UKCC CL4 award, affected the delivery days, it was useful to consider the interactionist assumption that individuals are capable to come together in groups and develop so-called joint acts (Blumer, 1969). Joint acts were described as collectively agreed behaviours that groups of individuals develop when evolving mutual understandings, expectations, and meanings Blumer (1969). In doing so, they develop acting units by aligning personal evaluations about one or more situations towards shared expectations. Whenever new situations arise, people need to develop interpretations for these undefined scenarios. To reach shared understandings, 
individuals require to fit together "different lines of individual conduct" and agree on "some division of labor" (Blumer, 1946, p. 167). While variation in behaviour is natural among members of acting units, mutual goals represent frameworks to make sense of the world in shared ways (Blumer, 1969).

When seeking to understand how university lecturer beliefs about postgraduate study informed their delivery and subsequently shaped learner perceptions of this delivery, it was useful to consider that interactions are informed by interpretations in situ as well as reflections on past behaviour, future aspirations, and the settings in which people operate (Blumer, 1969; Mead, 2015). It was suggested that human beings engage in self-indication when interpreting their own conduct in consideration of the perspectives that, they believed, others shared with them (Mead, 2015). They take into account things of interest and relevance, which inform thoughts, interpretations, and behaviours. In addition, meanings that a person has defined from past experiences and established understandings in a given context, so-called schemes of definition, shape conduct (Blumer, 1969). This can lead individuals to a variety of perceptions, interpretations, and interactions (Blumer, 1969). To evolve harmonious relationships, it was suggested that individuals must actively engage with the environment by taking into account and potentially revising situation-specific interpretations, longstanding assumptions, and opinions of the views others share with them (Mead, 2015).

In seeking to understand the value that coaches attached to postgraduate study and how this was shaped by their interactions with others, symbolic interactionist theorisation about status and its role as a social, contextualised, and evolving phenomenon were considered. It was suggested that human beings engage in many social settings, in which they continuously evolve skills and, with this, move between social positions (Strauss, 1997). The continuous development is marked by turning 
points that represent moments, when individuals recognise understandings that allowed movement to a new social status (Atkinson, 2017). Important when striving toward a new status, however, are not solely individual aspirations, but also widely held understandings that help people navigate social life, which were described as generalised other (Mead, 2015) and public opinion (Blumer, 1946). Considered socially accepted views, such perspectives represent norms that allow people with diverse histories to have some consensus when judging broadly understood aspects in a society. In this view, a person's perceived status is informed not only by individual interpretations, but also by other peoples' evaluations of how specific behaviours might fit with socially accepted and expected customs.

\section{Results and discussion}

Following on from the questions posed throughout the data analysis, the following areas were explored for the purpose of this paper: the (dis)joint(ed) conduct of GB and HEi personnel in the design of delivery days, educator and learner interactions during taught sessions, and the perceived value of the UKCC CL4 award as a reflection of coaches' status. Throughout this section, extracts from field notes and interviews (Table 1) were used to exemplify the observations made over the course of the fieldwork.

Table 1. Overview of participants quoted in this paper.

\begin{tabular}{l|l|l}
\hline UKCC CL4 context & Pseudonym & Role \\
\hline Combat sport & Toni & Coach \\
& Anna & Coach \\
\hline
\end{tabular}




\begin{tabular}{l|l|l}
\hline & Rick & Coach \\
& Ryan & Coach \\
Paul & University lecturer \\
Theo & University lecturer \\
& Jane & Technical Manager \\
Nicole & Level 4 liaison officer \\
\hline Water sport & Dan & Coach \\
& Grace & Coach \\
Steve & Coach \\
& Colin & Coach \\
& George & Coach \\
\hline
\end{tabular}

\section{(Dis)joint(ed) acts and course organisation}

The first theme explores the nature of the combat and water sport UKCC CL4 award with attention on the relations, responsibilities, and (lack of) mutually agrees acts among course organisers and their impact upon the layout of programme delivery days. Over the course of the fieldwork, it became apparent that differences existed in the design of the two programmes. In the water sport, GB and HEi personnel demonstrated division of responsibilities when organising taught sessions and leisure periods during residential days. They demonstrated what Blumer (1946) considered joint acts in pursuing agreed objectives, goals, and expectations. Their efforts created inviting 
atmospheres during residential events, which were reflected in the venues chosen for residential events that offered opportunities to reside in the same, catered accommodation. It was observed:

They really look after everyone. Before a residential, Lisa (Level 4 Programme Director) sends out details about schedule, accommodation, meals etc. There's always space to talk - between sessions, mornings, evenings. Lisa and at least two others from the Level 4 Board are there. People tend to stay at the venue. It's like entering a bubble for two days.

This contrasted with experiences with the combat sport, where delivery took place exclusively at the HEi. In this setting, the principal author was unclear at the start of her fieldwork, who organised residential events as she primarily met the university lecturers, who delivered sessions. The below notes are exemplary of the observational data:

I find it hard to make out who organises it. I've been in touch with Nicole from the HEi (Level 4 liaison officer), but it looks like the delivery is run without organisers around. HEi staff come, deliver and leave. Session by session. During breaks, coaches escape classrooms to grab food in the canteen or a nearby shop. It's a bit like I'm back on my Sport Science degree.

While it appeared the sole responsibility of one HEi staff to attend to the course organisation of the combat sport, a Level 4 Board (a group of GB and HEi staff) oversaw the water sport UKCC CL4 award and operated as an acting unit that shared organisational responsibilities. Conditions for the development of acting units included "that action takes place in and with regard to a situation" and "that the action is formed or constructed by interpreting the situation” (Blumer, 1969, p. 85). Members of the Level 4 Board members continuously made sense of the specific situations encountered on the UKCC CL4 award and used their interactions to agree shared responsibilities. 
Attendance of multiple, if not all board members during residential events facilitated dialogues in management meetings and impromptu conversations (Bandias et al., 2011). Regular interactions with one another enabled the course organisers to inform individual conduct with agreed objectives (Blumer, 1969). The following data extract was representative of the impression:

Only Nicole seems to organise the [combat sport] course. I think she has to oversee all of the residential delivery. The water sport course is different. A group of organisers get on with things. There's a split of responsibilities. The Level 4 Board members seem to fine-tune everything. They always seem on the same page. It makes a difference to the atmosphere during residentials.

The differences observed in the approaches to course design were reflected in the data gleaned from conversations with GB and HEi personnel. Rather than passively adopting pre-determined understandings about the programmes, the organisers were actively involved in defining meaning in the UKCC CL4 context. The programme represented a novel format of coach education that had to be accommodated with existing practice (Blumer, 1969). Harry (Head of Coaching, water sport) and Jane (Technical Manager, combat sport) explained:

We wanted and needed the university to accredit the PG Dip level, but we wanted to remain actively involved to retain some control as a Governing Body. We meet regularly with Evelyn (HEi liaison officer) and other HEi people. We meet with coaches. We know what is going on with the HEi, how coaches are doing. (Harry)

We had ideas that we wanted to put through. But we ended up leaving it to the university. I think it's the right way to go for a theory and research base. We didn't see a need for practical because we thought coaches could do that in their own time. But I'm beginning to think we need the sport more involved in organising and delivering ... I think we could do better. (Jane)

In a symbolic interactionist view, the meanings that organisers, such as Harry and Jane, 
defined with regard to the UKCC CL4 award were tied to past experiences, present responsibilities, and visions for the future (Charon, 2010), which could explain how those overseeing the course organisation had arrived at different interpretations. Nevertheless, as the fieldwork data revealed, GB and HEi personnel involved in the Level 4 Board of the water sport setting demonstrated that human beings were capable of developing joint acts (Blumer, 1969). The sharing of responsibilities while drawing on mutual understandings, which characterised joint acts, however, required groups of individuals to engage in "effective accommodation ... to one another" (Blumer, 1969, p. 86). This became particularly apparent when comparing the united efforts in the acting unit of the water sport Level 4 Board with the combat sport course organisation, which appeared left to one HEi staff member. Considering the absence of an acting unit guiding the everyday running of the course, the combat sport setting resembled a university degree rather than a postgraduate coach education programme that brought together academic insights with practitioner expertise (Townsend \& Cushion, 2017).

\section{Reciprocity in the educator-learner relationship}

Having observed differences in the organisation of the two programmes, it was of further interest how university lecturers, who acted as educators on the UKCC CL4 award, approached the delivery of sessions during residential events. The fieldwork revealed that coaches in both sports had mixed experiences with course delivery. Crucial to shaping learner perspectives were the ways in which university lecturers presented scientific knowledge to practitioner cohorts (Devlin \& Samarawickrema, 2010). In line with insights gained from studies investigating how mature learners perceived higher education delivery (Willans \& Seary, 2011), the coaches in this study 
felt more open to "buy into" postgraduate content when university lecturers presented it in an approachable manner. Anna, for example, considered it important to see how course content might fit with coaching practice:

It depended on the tutors how much I took from modules and wanted to look into areas. I struggled with PowerPoint and talk-type. I think the coach educators need to see more experience, more research on what coaches do and why it works for them. Then say, "Ok how can this benefit coaches coming through?"

Similarly, Rick stated:

Some have been better than others. Particularly Paul, our psychology guy, he's relatable. He makes it applied. You enjoy being in the lecture. Others ... biomechanics, for example, I studied it before, thankfully, but it was too physicslike. It's making it relatable, which I find good.

Dan valued sessions most, when he felt as though lecturers used his 20 years of practitioner expertise as the foundation for discussing postgraduate course content. $\mathrm{He}$ said:

Some lecturers set out the programme in ways that really builds on my 20 years of coaching. They challenged us but then they supported us to take those challenges and unpick them in a way that's pertinent to our own personal beliefs and philosophies. I'd say those sessions are the most powerful learning experience I've had in the last 20 years.

As the above-presented interview data illustrate, those university lecturers, who built on the expertise of coach learners, were perceived to have a refined understanding of the academic and practitioner emphasis of the programme. Sessions led by lecturers, who contextualised course content with situations encountered in the coaching process, were considered useful and enriched coaches' knowledge (Araya, Bennie, \& O'Connor, 2015; Galvan, Fyall, \& Culpan, 2012), while sessions without consideration of the practitioner 
cohort lacked applicability and relevance (Chesterfield, et al., 2010; Jones \& Allison, 2014; Nelson, Cushion, \& Potrac, 2013; Townsend \& Cushion, 2017). For coach learners, it was important that the university lecturers revaluated longstanding practices and, in their delivery, considered factors that could affect coach learning (Spies \& Botma, 2015). In doing so, the lecturers engaged in what Mead (2015) described as selfindication, which in the context of this study, represented active and context-specific interpretation, recognition, and consideration of the things that characterised delivery on the UKCC CL4 award. According to Mead (2015), the more a person was able to identify and interpret the actions of others, the more they could refine their awareness of others. In turn, enhanced awareness of self and others helped the development of transaction, reciprocal interaction that is characterised by continuous "definition and redefinition of one another's action" (Blumer, 1969, p. 110), which could aid meaning creation and learning in educational environments (Damşa \& Ludvigsen, 2016). In this study, the extent to which university lecturers recognised the specific contexts of the UKCC CL4 award shaped their delivery and subsequently, coaches' perceptions of course content and lecturers themselves. Consideration of coach learners as practitioners, who might struggle with prolonged presentations of course content, however, enjoyed discussions about the same content, led coaches to describe sessions as "powerful" and "relatable" as Dan and Marcus described, respectively.

Speaking to university lecturers, it became apparent that the delivery on the UKCC CL4 award represented a balancing act between practitioner demands, postgraduate expectations, and longstanding practices. As an example, Paul, a university lecturer, who delivered sessions on the combat sport CL4 award, described:

I guess the coaches don't necessarily come from academic backgrounds. As an educator, understanding those differences and applying things in different ways, 
approaching classroom sessions in different ways. It still has to be of a level 7 standard, but we have to take into account the non-academic background.

Similarly, Theo, also a university lecturer, noted:

In my opinion, if you're gonna be teaching coaches, you have to have a hybrid academic. The academic has to have practical experience or they need to actively reflect on how they want to teach coaches.

Evelyn described the challenges lecturers faced in the delivery on the UKCC CL4 award:

I think with all education we should be starting with the individual learner and what are their requirements for the individual. The challenge that we have is that the CL4 award is benchmarked at postgraduate levels, so it needs to be standardised and all that, you know it needs to meet certain criteria. So it's tempting for us [lecturers] to be more generic and just deliver what we normally offer on our Masters. But I think the tutors [lecturers] need to take what they normally do, identify the needs of those individuals and tailor the courses so that they still meet the requirements of the qualification but that it also meets the individuals' needs as well. But that's the challenge because it's easy to just go back to what we know.

University lecturers, such as Paul, Theo, and Evelyn, recognised that their delivery approaches were aligned with the meanings that they had defined about education, socalled schemes of definition (Blumer, 1969), which were based on their experiences and established understandings of HEi provision. Rendering a sense of order and continuity to individual interpretations, schemes of definition help a person control responses to the things they encounter. However, schemes of definition would merely guide behaviour (Blumer, 1969). As the university lecturers in this paper recognised, it was the responsibility of the individual to choose appropriate existing understandings or develop new definitions to make sense of a situation (Mead, 2015). As the interview 
data gathered from coach learners revealed, university lecturers' purposeful preparation of course content explicitly for the practitioner cohorts completing the UKCC CL4 award, did not only shape coaches' perceptions of coach education, but also their consideration of course content for coaching practice.

\section{A symbol of status}

Given the mixed experiences of coaches with the delivery of the UKCC CL4 award, it was of interest what value they associated with it. This section therefore explores the perceived progression, status, and importance of recognition from others described in conversations about the value of the postgraduate coach education programme. At the time of this study, course organisers had observed coaches' progression, as for instance Lisa, Level 4 Programme Director, noted:

Our people finishing or in the system change the way they go about what they do. I can see they're influencing the world they exist in, running their own business or working for somebody else. There's change within national centres.

Conversations with coach learners reflected that increased feelings of competence and confidence with research-informed understandings were seen to facilitate a cascading of information into everyday practice (Hammond \& Feinstein, 2005). For instance, Grace was hoping to inform her sport in the following way:

I will be the first in the region to have a level four qualification. I hope to go to other clubs and share what I've learned. Promote the value of being a good coach, what that means to people who've been coaching a long time, who might be stuck or isolated. I see myself in an ambassadorial role. (Grace)

Others integrated novel understandings as coach education tutors: 
I teach on level 3, 2 and 1. Having the Level 4 is vital for me as a coach educator ... the top level we offer is the Level 4, so it makes sense to have it. As a role model, I suppose. Also I can relate to what the courses involve from a learner perspective. (Ryan)

I got new ideas how to take what I do, a step further. Now I know I could, if I wanted to move to another university or decide to alter position where I am now. I do a lot of coach or instructor education. I have seen this trickle down into that. I feel up-to-date with best practice, confident to use academic language when I instruct others. (Steve)

Although none of the participants criticised the course for lacking value or significance, several coaches in both sports placed emphasis on its postgraduate outcome, which symbolised progression and credibility. Similar to understandings gained from the higher education literature (Tight, 2012), the participants in this study associated engagement with postgraduate study with learning and working at a "higher" level. Thinking about their professional future, Anna and Toni explained:

I want to be ahead of the game. I want to command better positions, which I'm capable of doing, but I need backing for more credibility. I wanted to have something to say, "I've been through this, I've got this qualification." Academic backing helps underline that. (Anna)

I have experience, but I need something at the end of my name that says I coached a gold medal (athlete). To increase credibility. The PG Dip and Masters give me opportunity to be employed in different situations, an educational establishment. My experience doesn't. I'm looking at ... at my existence beyond sport. (Toni)

The above-presented interview extracts reveal how coaches framed their completion of postgraduate coach education as an opportunity to progress in their professional careers (Kenner \& Weinerman, 2011). As a series of phases through which people move over the course of time, professional life can be considered in continuous flux, which 
allowed adoption of different roles in various social settings and with this, passage from one status to another (Strauss, 1997). For the coaches in this study, postgraduate study on the UKCC CL4 award brought into reach new positions within and outside sports coaching. Significant to such status passage were turning points that represented "points in development when an individual has to take stock, to re-evaluate, revise, resee, and rejudge" assumptions and social positions (Strauss, 1997, p. 102). As markers "of progression ... milestone[s]" they represent moments when individuals become aware of developments that could be used to reach a new status (Strauss, 1997, p. 95). The coaches in this study noticed an increase in confidence and confirmation of competence from completing postgraduate study (Hammond \& Feinstein, 2005).

Coaches attached particular importance to reaching a new "social position" that held recognisable cultural custom and encouraged recognition from others (Atkinson, 2017, p. 85). Why it was so important to be seen to operate at an elevated level from engagement with postgraduate study became particularly evident in comments relating to coaches' experiences of remarks that others had passed about coaching as an occupation. Colin recollected:

\footnotetext{
"What do you do for a real job?" is a comment I've heard quite a lot. The Level 4 is a good step forward to show this is what I'm doing as a profession and it is worthwhile. Everyone will see I've got an academic qualification. That means something to people.
}

George said:

"Oh you're just a coach." You wouldn't say to my wife, "Oh you're just a teacher." I think there's a big lack of knowledge in the community that it is a full-time profession. For that, I think it is really beneficial to have the link to university.

It became apparent that an awareness of and experiences with the views that others held 
about the sports coaching profession, affirmed the significance of completing a postgraduate programme. The widely held perspectives that friends and family drew upon to judge what sports coaching was and what coaches did, could be viewed as what was termed generalised other (Mead, 2015) and public opinion (Blumer, 1946). The concepts describe "a collective product" of widely held opinions and fundamental tendencies on things that are of central consideration in social groups underpinning individual opinions and rendering a sense of unity regarding widely understood things (Blumer, 1946, p. 191). As the findings indicate, broadly held opinions relating to what was considered integral to a profession and the implications for sports coaching became apparent in the participant perspectives. In particular, coach learners felt that those, who were not necessarily involved with the coaching profession regarded sports coaching as a leisurely activity. Arguably, the practitioners had internalised the views others shared with them as a generalised other that contributed to their view of the UKCC CL4 award as strengthening of their credibility as full-time professionals. In particular, the lack of endorsement from others affected coaches' value associated with postgraduate study and certification. The participants appeared to find comfort in the knowledge that generalised understandings did exist in regard of postgraduate qualifications and that HEi accreditation for the PG Dip could contribute to professional recognition (Bravenboer \& Lester, 2016).

\section{Conclusions}

The present study sought to better understand the interactions and practices of coaches, coach educators (i.e. university lecturers), and coach education managers in two UKCC CL4 awards. The findings reveal that the assignment of multiple GB and HEi personnel 
with willingness and capacity for interdisciplinary collaborations, jointly agreed conduct, and regular interactions were essential to offering research-informed, coaching-relevant coach education (Green \& Johnson, 2015). During taught sessions, coaches' interactions with university lecturers played a key role in shaping coaches' perceptions of the programmes. In line with previous work that described effective higher education delivery as a balancing act (e.g., of curriculum, content relevance, instruction, feedback, self-directed learning) (Sogunro, 2015), the extent to which lecturers considered coaches' skills and adapted postgraduate delivery, shaped coaches' opinions of delivery quality and educator abilities. Irrespective of the adopted delivery styles, however, the participants recognised postgraduate study as important to enhancing coaches' credibility and external recognition. Similar to adult learners in higher education environments (e.g., Sogunro, 2015), the coaches succeeded to look beyond the challenges encountered when engaging with academic study and recognised its potency to their professional status and careers.

Similar to studies that highlighted a need to consider potential tensions between practitioner roles and academic study when working with mature students (e.g., Spies \& Botma, 2015; Willans \& Seary, 2011), the coaches in this study described their experiences of postgraduate study as shaped by how lecturers designed sessions rather than criticising the delivered content itself. How the university lecturers designed their delivery and coaches subsequently perceived it was not aligned to the ways in which management teams organised the two studied UKCC CL4 awards. This observation warrants further attention. Future research might seek to understand how stakeholders manage their relationships with individuals not only in their own organisations (i.e. their GB or HEi) but also with organisational partners (e.g., other GBs, HEis, and UK Coaching). Equally, it would be worthwhile to explore how university lecturers' 
understandings of environments, demands, and expectations in their workplaces facilitate and constrain pedagogical decisions (Vostal, 2015).

Although the present study findings may mirror understandings gained about adult learners in higher education (e.g., Bandias et al., 2011; Chugai et al., 2017; Spies \& Botma, 2015), the primary aim of this study was to contribute toward new knowledge in the coach education literature. The use of symbolic interactionist theory (Blumer, 1946; 1969; Mead, 2015; Strauss, 1997) was particularly useful to make sense of coach education as an inherently social and context-dependent process that is informed and, equally, informs individual opinions and interpersonal practices of coaches, coach educators, and coach education managers (Nelson et al., 2016). The theoretical positioning of symbolic interactionism facilitated understandings that extend beyond previous research, which explored coaches' perceptions of coach education programmes (e.g., Araya, et al., 2015; Galvan, et al., 2012; Jones \&Allison, 2014; Townsend \& Cushion, 2017). In particular, interpretations of individual meanings, collective behaviours, and interpersonal encounters of coaches, coach educators, and coach education managers as social, fluid, and emerging in situations of the UKCC CL4 award (Rock, 2001).

The present study also raises important questions and considerations for those involved in the design and delivery of coach education. It would be useful for coach education developers to reflect upon how they manage coach education programmes with regard to what they are hoping to achieve with the layout of their provision. In particular, it would be important to define roles and responsibilities of individual stakeholders clearly, revisit them regularly, and to view intra- and inter-organisational partnerships as relationships that require long-term planning and continuous development. Furthermore, it would be useful to consider who should deliver 
(postgraduate) coach education programmes, which everyday pressures and challenges these individuals experience, and therefore what support might be useful for them. Given that the coaches in this study valued postgraduate study in spite of different programme designs and mixed experiences with educators, it is time for coach education developers to reflect also on the reasons for which coaches might place such significant value on academic study. Although these considerations might challenge existing practices and structures, such knowledge could usefully inform the development of a coach education workforce that is equipped to integrate diverse interests, goals, and agendas and pursue the implementation of research-informed, practice-related conduct in practitioner and academic domains.

\section{Acknowledgements}

We thank the management teams and participants involved in the combat and water sport UKCC CL4 award for enabling access to the courses. We also thank UK Coaching for subsidising the travel cost incurred throughout this study.

\section{References}

Adler, P. A., \& Adler, P. (1987). Membership roles in field research. Thousand Oaks: SAGE Publications.

Araya, J., Bennie, A., \& O'Connor, D. (2015). Understanding performance coach development: Perceptions about a postgraduate formal coach education program. International Sports Coaching Journal, 2(1), pp. 3-14.

Atkinson, P. (2017). Thinking ethnographically. London: SAGE Publications.

Bandias, S., Fuller, D., \& Pfitzner, D. (2011). Vocational and higher education in Australia: A need for closer collaboration. Journal of Higher Education Policy and Management, 33(6), pp. 583-594. 
Blumer, H. (1946). The field of collective behavior. In A. McClung Lee (Ed.), New outline of the principles of sociology (pp. 167-169). New York: Barnes \& Noble, Inc.

Blumer, H. (1969). Symbolic interactionism: Perspective and method. New Jersey: Prentice-Hall Inc.

Braun, V., Clarke, V., \& Weate, P. (2016). Using thematic analysis in sport and exercise research. In B. Smith \& A. C. Sparkes (Eds.), Routledge handbook of qualitative research in sport and exercise (pp. 191-205). Abingdon: Routledge.

Bravenboer, D., \& Lester, S. (2016). Towards an integrated approach to the recognition of professional competence and academic learning. Education + Training, 58(4), pp. 409-421.

Brinkmann, S., \& Kvale, S. (2018). Doing Interviews (2nd ed.) London: SAGE Publications.

Bucholtz, M. (2000). The politics of transcription. Journal of pragmatics, 32(10), pp. 1439-1465.

Charon, J. M. (2010). Symbolic interactionism: An introduction, an interpretation, an integration Boston: Pearson.

Chesterfield, G., Potrac, P., \& Jones, R. (2010). ‘Studentship'and 'impression management' in an advanced soccer coach education award. Sport, Education and Society, 15(3), pp. 299-314.

Chugai, O., Terenko, O., \& Ogienko, O. (2017). Methods that work: Best practices of adult educators in the USA. Advanced Education, 4(8), pp. 72-77.

Cousin, G. (2009). Researching learning in higher education: An introduction to contemporary methods and approaches. London: Routledge.

Damşa, C. I., \& Ludvigsen, S. (2016). Learning through interaction and co-construction of knowledge objects in teacher education. Learning, Culture and Social Interaction, 11, pp. 1-18.

Denzin, N. K. (1992). Symbolic interactionism and cultural studies: The politics of interpretation. Cambridge: Blackwell Publishers.

Devlin, M., \& Samarawickrema, G. (2010). The criteria of effective teaching in a changing higher education context. Higher Education Research \& Development, 29(2), pp. 111-124. 
Ellis, C. (2004). The ethnographic I: A methodological novel about autoethnography. Walnut Creek: Rowman Altamira.

Emerson, R. M., Fretz, R. I., \& Shaw, L. L. (2001). Participant observation and fieldnotes. In P. Atkinson, A. Coffey, S. Delamont, J. Lofland \& L. Lofland (Eds.), Handbook of ethnography (pp. 352-368). London: SAGE Publications.

Galvan, H., Fyall, G., \& Culpan, I. (2012). High-performance cricket coaches' perceptions of an educationally informed coach education programme. AsiaPacific Journal of Health, Sport and Physical Education for Health, 3(2), pp. 123-140.

Green, B. N., \& Johnson, C. D. (2015). Interprofessional collaboration in research, education, and clinical practice: Working together for a better future. Journal of Chiropractic Education, 29(1), pp. 1-10.

Gubrium, J. F., \& Holstein, J. A. (2003). Postmodern interviewing. London: SAGE Publications.

Guillemin, M., \& Gillam, L. (2004). Ethics, reflexivity, and "ethically important moments" in research. Qualitative inquiry, 10(2), pp. 261-280.

Hammersley, M., \& Atkinson, P. (2007). Ethnography: Principles in practice. London: Routledge.

Hammond, C., \& Feinstein, L. (2005). The effects of adult learning on self-efficacy. London Review of Education, 3(3), pp. 265-287.

He, C., Trudel, P., \& Culver, D. M. (2018). Actual and ideal sources of coaching knowledge of elite Chinese coaches. International Journal of Sports Science \& Coaching, 0(0), pp. 1-12.

Iloh, C., \& Tierney, W. (2014). Using ethnography to understand twenty-first century college life. Human Affairs, 24(1), pp. 20-39.

Jones, R., \& Allison, W. (2014). Candidates' experiences of elite coach Education: A longitudinal study ('Tracking the journey'). European Journal of Human Movement, 33(33), pp. 110-122.

Kasworm, C. E. (2010). Adult learners in a research university: Negotiating undergraduate student identity. Adult Education Quarterly, 60(2), pp. 143-160.

Kenner, C., \& Weinerman, J. (2011). Adult learning theory: Applications to nontraditional college students. Journal of College Reading and Learning, 41(2), pp. 87-96. 
Lucas, L. (2012). Ethnographic journeys in higher education. In S. Delamont (Ed.), Handbook of qualitative research in education (pp. 170-180). Cheltenham: Edward Elgar Publishing.

McCall, G. J. (2006). The fieldwork tradition. In D. Hobbs \& R. Wright (Eds.), The SAGE handbook of fieldwork (pp. 3-22). London: SAGE Publications.

Mead, G. H. (2015). Mind, self \& society - The definitive edition. Chicago: University of Chicago Press.

Nelson, L., Cushion, C., \& Potrac, P. (2013). Enhancing the provision of coach education: the recommendations of UK coaching practitioners. Physical Education and Sport Pedagogy, 18(2), pp. 204-218.

Nelson, L., Groom, R., Potrac, P., \& Marshall, P. (2016). Herbert Blumer: Coaching and coach education as symbolic interaction. In L. Nelson, R. Groom \& P. Potrac (Eds.), Learning in sports coaching: Theory and application (pp. 177188). London: Routledge.

Rock, P. (2001). Symbolic interactionism and ethnography. In P. Atkinson, A. Coffey, S. Delamont, J. Lofland \& L. Lofland (Eds.), Handbook of ethnography (pp. 2638). London: SAGE Publications.

Smith, B., \& McGannon, K. R. (2018). Developing rigor in qualitative research: Problems and opportunities within sport and exercise psychology. International Review of Sport and Exercise Psychology, 11(1), pp. 101-121.

Sogunro, O. A. (2015). Motivating factors for adult learners in higher education. International Journal of Higher Education, 4(1), pp. 22-37.

Spies, C., \& Botma, Y. (2015). Adult learning: What nurse educators need to know about mature students. Curationis, 38(2), pp. 1-7.

Sports Coach UK. (2015). UKCC support guide (Levels 1-4). Leeds: Sports Coach UK. Stephens, N. (2010). Collecting data from elites and ultra elites: Telephone and face-toface interviews with macroeconomists. In P. Atkinson \& S. Delamont (Eds.), SAGE qualitative research methods (pp. 204-216). Thousand Oaks: SAGE Publications.

Strauss, A. L. (1997). Mirrors and masks: The search for identity. New Brunswick: Transaction Publishers.

Tight, M. (2012). Key concepts in adult education and training (2nd ed.) London: Routledge. 
Townsend, R. C., \& Cushion, C. (2017). Elite cricket coach education: A Bourdieusian analysis. Sport, Education and Society, 22(4), pp. 528-546.

Trede, F., Macklin, R., \& Bridges, D. (2012). Professional identity development: A review of the higher education literature. Studies in Higher Education, 37(3), pp. 365-384.

Vostal, F. (2015). Academic life in the fast lane: The experience of time and speed in British academia. Time \& Society, 24(1), pp. 71-95.

Werthner, P., \& Trudel, P. (2009). Investigating the idiosyncratic learning paths of elite Canadian coaches. International Journal of Sports Science and Coaching, 4(3), pp. 433-449.

Willans, J., \& Seary, K. (2011). 'I feel like I'm being hit from all directions': Enduring the bombardment as a mature-age learner returning to formal learning. Australian Journal of Adult Learning, 51(1), pp. 119-142.

Wolcott, H. F. (2008). Ethnography - A way of seeing. (2nd ed.) Lanham: AltaMira Press. 


\section{Appendix 1}

Table 2. Overview of all study participants.

\begin{tabular}{l|l}
\hline Participant group & Number of participants \\
\hline Coaches & 32 \\
Coach educators (GB and HEi staff) & 17 \\
Coach education managers & 4 \\
\hline Total & 53 \\
\hline
\end{tabular}

Table 3. Combat sport UKCC CL4 award: Overview of participants.

\begin{tabular}{l|l}
\hline Participant group & Number of participants \\
\hline Coaches & 21 \\
Coach educators (GB and HEi staff) & 10 \\
Coach education managers & 2 \\
\hline Total & 33 \\
\hline
\end{tabular}

Table 4. Water sport UKCC CL4 award: Overview of participants.

\begin{tabular}{l|l}
\hline Participant group & Number of participants \\
\hline Coaches & 11 \\
Coach educators (GB and HEi staff) & 7 \\
Coach education managers & 2 \\
\hline Total & 20 \\
\hline
\end{tabular}




\section{Appendix 2}

Table 5. Overview of participants, who took part in interviews.

\begin{tabular}{l|l|l}
\hline UKCC CL4 context & Participant group & Number of participants \\
\hline Combat sport & Coaches & 14 \\
& Coaches educators & 6 \\
& Coach education managers & 1 \\
\hline Water sport & Coaches & 10 \\
& Coach educators & 5 \\
& Coach education managers & 2 \\
\hline
\end{tabular}

Table 6. Overview of semi-structured interviews.

\begin{tabular}{l|l}
\hline Participant group & Number of interviews \\
\hline Coaches & 32 \\
Coach educators & 13 \\
Coach education managers & 6 \\
\hline Total & 51 \\
\hline
\end{tabular}

